Research Paper

\title{
Efficacy and Safety of Intro-Arterial Chemotherapy Combined with Radiotherapy on Head and Neck Cancer: A Systematic Review and Meta-Analysis
}

\author{
Yan Huang1, Li-Ling Wu², Ruo-Lan Xiang ${ }^{2 \bowtie}$, Guang-Yan Yu ${ }^{1 凶}$ \\ 1. Department of Oral and Maxillofacial Surgery, Peking University School and Hospital of Stomatology, Beijing, 100081, China. \\ 2. Department of Physiology and Pathophysiology, Peking University School of Basic Medical Sciences, Key Laboratory of Molecular Cardiovascular Sciences, \\ Ministry of Education, and Beijing Key Laboratory of Cardiovascular Receptors Research, Beijing, 100191, China. \\ $\square$ Corresponding authors: Dr. Ruo-Lan Xiang, Department of Physiology and Pathophysiology, Peking University School of Basic Medical Sciences, No. 38 \\ Xueyuan Road, Haidian District, Beijing, 100191, China. Email address: xiangrl@bjmu.edu.cn; Phone: 0086-10-82801403. Dr. Guang-Yan Yu, Department of Oral \\ and Maxillofacial Surgery, School and Hospital of Stomatology, Peking University, No. 22 Zhong Guan Cun South Street, Haidian District, Beijing, 100081,
} China. Email address: gyyu@263.net; Phone: 0086-10-82195245.

() The author(s). This is an open access article distributed under the terms of the Creative Commons Attribution License (https://creativecommons.org/licenses/by/4.0/). See http://ivyspring.com/terms for full terms and conditions.

Received: 2019.05.08; Accepted: 2019.09.06; Published: 2019.10.17

\begin{abstract}
Objectives: Intro-arterial chemotherapy combined with radiotherapy (IACRT) for the treatment of head and neck cancer (HNC) underwent a revival in recent years. Although many clinical trials have reported favorable outcomes, the effect of IACRT for HNC is still controversial. Therefore, this study was designed to evaluate the efficacy and safety of IACRT for HNC.

Methods: The relevant articles published before August 2019 were searched from PubMed, Embase, Cochrane Library, Web of Science and PMC databases. Data were extracted and the combined complete response (CR), overall survival (OS) and toxicity incidence with $95 \%$ credible interval $(\mathrm{Cl})$ were examined from eligible studies.

Results: Thirty-four studies comprising 1890 patients were included. IACRT achieved high CR (0.81, 95\% Cl: $0.76-0.86, P<0.001)$, 3-year OS $(0.75,95 \% \mathrm{Cl}: 0.68-0.82, P<0.001)$ and 5 -year OS $(0.68,95 \% \mathrm{Cl}: 0.61-0.75, P<0.001)$. The 3-year OS rate of stage III cancer $(0.75,95 \% \mathrm{Cl}: 0.53-0.97$, $P<0.001)$ was higher than stage IV $(0.52,95 \% \mathrm{Cl}: 0.37-0.66, P=0.025)$. Meanwhile, the 5 -year OS of T3 cancer $(0.87,95 \% \mathrm{Cl}: 0.73-1.01, P=0.028)$ was higher than T4 $(0.53,95 \% \mathrm{Cl}: 0.42-0.63, P=$ 0.286 ). Additionally, oral diseases, mucositis, leukopenia and dermatitis were the major toxicities of IACRT, which were all reversible.

Conclusion: IACRT is an efficient and safe modality for HNC, which could achieve favorable cancer response and higher survival rate with acceptable toxicities, even for advanced HNC.
\end{abstract}

Key words: intro-arterial chemoradiotherapy, head and neck cancer, complete response, overall survival, toxicity

\section{Introduction}

Head and neck cancer (HNC) is the 6th most common malignancy worldwide, most patients presented advanced stage when diagnosed, which was characterized by low 5-years survival rate and poor prognosis [1-3]. The traditional treatments for HNC are surgery, radiotherapy and chemotherapy. Owing to the complexity of structure and the need for organ preservation, these traditional treatments for HNC have many limitations. Cancers with invasion to deep and important location or with multiple distant metastases are unresectable $[4,5]$. Moreover, surgical treatment would cause a significant decrease in physical function and cosmetic impairment. Radiation therapy often induces many adverse effects such as oral mucositis, osteoradionecrosis, tissue fibrosis and salivary gland dysfunction [6, 7]. Therefore, novel therapies with stronger effect and lower toxicity are urgently needed. 
Since most HNCs are insensitive to anticancer drugs, chemotherapy alone is not a preferred treatment for HNC [8]. It is usually combined with radiation therapy. Early practice was mainly focus on intra-versus chemotherapy combined with radiotherapy (IVCRT), although there are certain advances by employing IVCRT, the results of HNC patients are still unsatisfactory, due to low drug level in cancer site and high drug level in circulatory system. In recent years, intra-arterial chemotherapy combined with radiotherapy (IACRT) for HNC attracts many attentions, which was proved to get favorable results in many clinical trials, especially after advanced angiographic techniques developed, permitting the infusion of drugs superselectively into tumor feeding arteries $[9,10]$. The greatest advantages of IACRT are increased drug concentration at the tumor bed and mild systemic toxicity due to relatively low level of the drug in blood circulation [11]. Robbins and his co-workers inserted a catheter into femoral artery with cisplatin, which reported to achieve high percentage of local control without increasing adverse effects in advanced carcinoma of the head and neck $[12,13]$. Mitsudo et al. achieved high complete response $(\mathrm{CR}=95.8 \%)$ and 3-year overall survival (OS $=81.5 \%$ ) through using retrograde superselective IACRT for tongue cancer [14]. Although many studies showed favorable outcomes, there are still some controversies. Some investigations only obtain poor CR rate $(38.5 \%)$ and lower 5-year OS rate (39.5\%) [15, 16]. Therefore, the exact efficacy of IACRT remains controversial, especially for cancers in different stages, which may be more valuable for clinicians.

Therefore, this meta-analysis was conducted to evaluate the efficacy and safety of IACRT on the treatment of HNC patients. Furthermore, by dividing patients according to the stages, we attempted to analyze IACRT efficacy in different stage HNC, which may provide the summarized and evidence-based information for clinicians in treating HNC patients.

\section{Methods}

This systematic review and meta-analysis was complied with PRISMA Statement [17].

\section{Search strategy}

We manually searched and selected documents with the following search terms: "radiation therapy" and "intra-arterial chemotherapy" or "intra-arterial drug administration" and "mouth cancer" or "mouth carcinoma" or "tongue carcinoma" or "mouth tumor" or "salivary gland tumor" or "parotid gland tumor" or "tongue tumor" or "pharynx tumor" or "tonsil tumor" or "oral cancer" or "oral tumor" or "mouth squamous cell carcinoma" or "gingival carcinoma" or "carcinoma of gingiva" or "oropharynx carcinoma" or "head and neck cancer" or "head and neck tumor" from PubMed, Embase, Cochrane Library, Web of Science and PMC databases. Additionally, we search original published articles, reviews, references cited in the relevant review articles, conference abstracts and the publications of experts up to August 2019 to find the related articles.

\section{Study selection}

All literatures were manually read and screened in dependently by two reviewers (Y. Huang and R.L. Xiang). Any discrepancies between the two reviewers were solved by a consensus. Animal studies and non-English articles were excluded. If the review includes raw data, detailed examination of the full text will lead the studies to be included or excluded. If there were duplicate studies, we choose articles published most recently or providing more detailed information. If review contains raw data, it will also be included.

\section{Data extraction and quality assessment}

An investigator used a pre-designed structure table to extract data from each eligible study, another investigator independently reviewed the data to ensure accuracy. Eligible trials have to satisfy the Participants, Intervention, Comparison, Outcomes, and Setting (PICOS) criteria: (1) Participants: HNC patients, (2) Intervention: intra-arterial chemoradiotherapy, (3) Comparison: no comparison, (4) Outcomes: CR or OS of IACRT therapy, (5) Setting: most studies are retrospective studies. The studies of intra-arterial chemotherapy (IACT) without radiotherapy were not included. Additionally, we included one RCT and three prospective studies, but only data from the IACRT group were used.

Since most of the studies included were single-arm cohort studies, we used the CASP-Cohort-Study-Checklist to assess the quality of the studies. Two authors (Y. Huang and R.L. Xiang) assessed the quality and risk of bias in the eligible studies independently. Disagreements were solved through discussion and reevaluation.

\section{Statistical analysis}

We evaluated therapeutic effect of IACRT in the treatment of HNC by assessing CR and OS with their 95\% credible interval from included trials, and drawing plotted forest map according to the results. We also performed a subgroup analysis to assess the impact of IACRT to different stage HNCs. A combined analysis of OS in the graded patients was conducted including the 3-year OS of stage III and stage IV cancers as well as the 5-year OS of T3 and T4 cancers. Furthermore, we calculated toxicity incidence 
with $95 \%$ credible interval of enrolled reports to assess the safety of IACRT. All statistical analyses were conducted by using Stata14 statistical software, and a $P<0.05$ was considered to have statistical significance. $I^{2}$ statistics were used to measure statistical heterogeneity. If $I^{2}>50 \%$, a random-effect model was used, otherwise, a fixed-effect statistical model was used. Stata 14 Egger's test and Begg's funnel plot were used to assess publication bias, $P$ value lower than 0.05 were judged as statistically significant, indicating that the study has publication bias.

\section{Results}

\section{Eligible studies}

A search in PubMed, Embase, Cochrane Library, Web of Science and PMC databases yielded a total

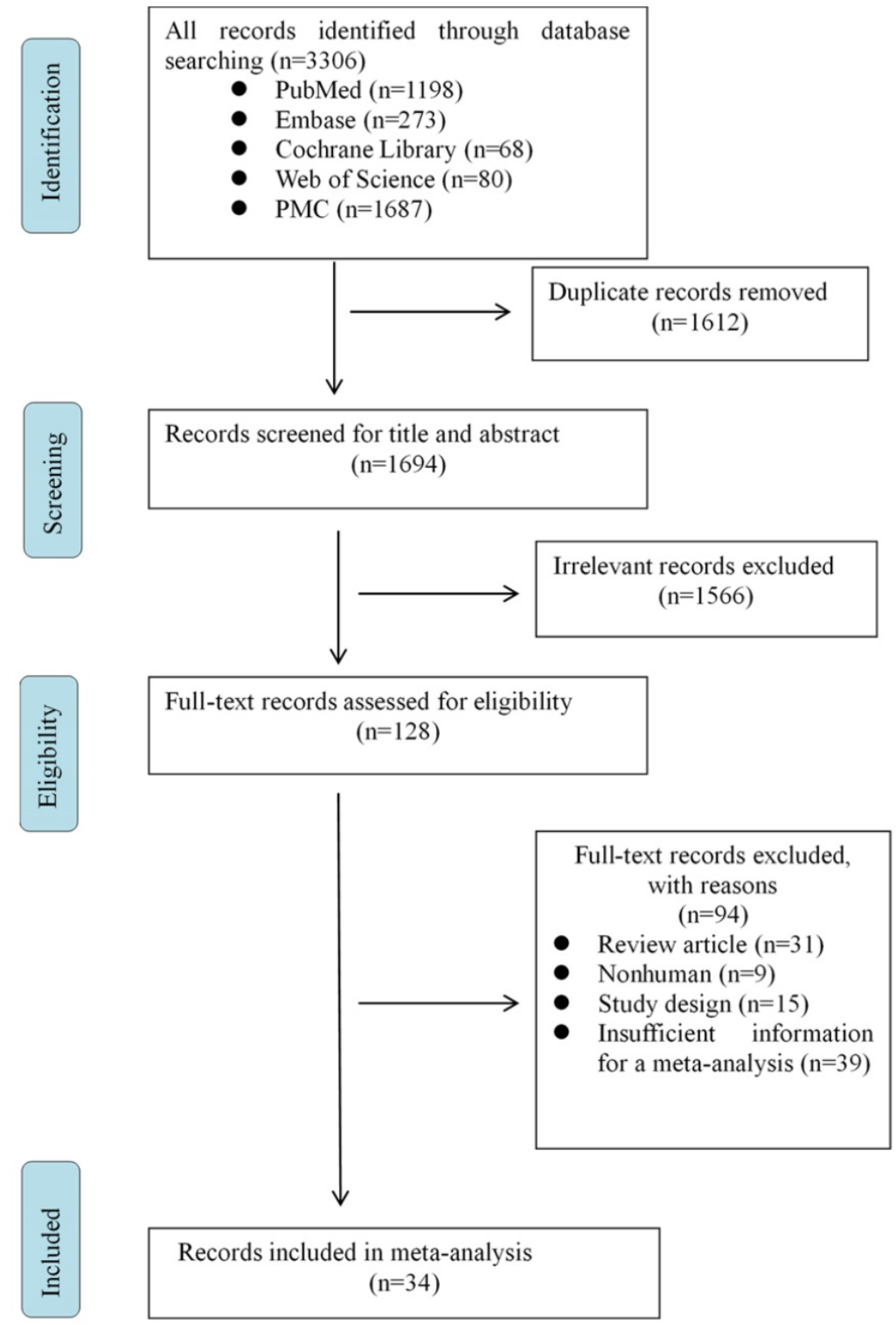

Figure 1. Flow program of eligible studies. number of 3306 articles. After removing duplicated and irrelevant records, only 128 full-text articles remained for eligibility. We then excluded the following studies: review article, nonhuman study, study design, insufficient information for meta-analysis. Finally, 34 papers were identified for the present meta-analysis (Fig. 1).

\section{Study characteristics}

The meta-analysis included 34 studies consisting with a total number of 1890 patients. Among which 27 studies were from Japan, 3 studies were from Italy, others were from USA, Korea, Germany and Macedonia, respectively. Ten types of HNCs were investigated in this meta-analysis, including squamous cell carcinoma (SCC) of tongue, gingiva, mouth floor, buccal, palate, larynx, oropharynx, maxillary sinus, paranasal sinus and nasal natural killer/T-cell lymphoma (NNKTL). Among these records, 30 were retrospective studies, 3 were prospective study, only one was randomized controlled trial (RCT). Moreover, 5 studies provided 5-year OS rate, 9 studies reported both 5-year OS and CR rates, 10 studies assessed both 3-year OS and CR values, and just 5 studies estimated all 3-year OS, 5 -year OS and CR values. The detailed information of each study was listed in Table 1.

\section{Results of individual studies and data synthesis}

\section{Complete response (CR)}

CR refers complete clearance of the lesion after treatment, which directly reflects the clinic efficiency of cancer treatment. Twenty-nine studies containing 1382 patients were enrolled to evaluate CR value, in which, 24 studies presented high CR rates ranging from $0.71-1.00$. Furusaka et al. achieved $96 \%, 86 \%$ and $94 \%$ CR rates in SCC of tongue, hypopharyngeal piriform sinus and anterior oropharyngeal wall, respectively [20-22]. Additionally, $73 \%$ and $84 \%$ of CR rates were reported by Fuwa et al. using carboplatin and cisplatin, respectively [16, 23]. Only 2 studies had relatively lower CR rates of 0.22 (95\% CI: $0.03-0.42$ ) and 0.38 (95\% CI: 0.25-0.52). The combined CR value was up to 0.81 (95\% CI: $0.76-0.86, P<0.001)$. Heterogeneity in these studies was higher than $50 \%\left(I^{2}=\right.$ $87.8 \%$ ), so we used a random-effect model (Fig. 2). 
Table 1. Characteristics of enrolled studies.

\begin{tabular}{|c|c|c|c|c|c|c|c|c|c|c|}
\hline Study & Year & Study design & Cancer type & Age & $\begin{array}{l}\text { Male } \\
(\%)\end{array}$ & T classification & $\begin{array}{l}\text { Sample } \\
\text { size }\end{array}$ & $\begin{array}{l}\text { Follow-up } \\
\text { (y) }\end{array}$ & Country & $\begin{array}{l}\text { Outcome } \\
\text { measured }\end{array}$ \\
\hline Arcangeli [18] & 1983 & $\mathrm{RCT}$ & SCC & - & - & $\mathrm{T} 2-\mathrm{T} 4$ & 142 & 5 & Italy & $5-y$ OS \\
\hline Fujishiro [19] & 2007 & Retrospective study & Maxillary sinus carcinoma & 62 & 78.6 & $\mathrm{~T} 2-\mathrm{T} 4 \mathrm{~b}$ & 14 & 2.1 & Japan & CR, 3-y OS \\
\hline Furusaka [20] & 2012 & Retrospective study & Tongue SCC & $66.4[37-81]$ & 75.6 & $\mathrm{~T} 2-\mathrm{T} 4 \mathrm{~b}$ & 45 & 3.2 & Japan & CR, 5-y OS \\
\hline Furusaka [21] & 2013 & Retrospective study & $\begin{array}{l}\text { Hypopharyngeal piriform } \\
\text { sinus SCC }\end{array}$ & $64.1[37-74]$ & 93 & T3-T4b & 57 & 5.3 & Japan & CR, 5-y OS \\
\hline Furusaka [22] & 2013 & Retrospective study & Oropharyngeal SCC & $64.6[37-86]$ & 74.5 & $\mathrm{~T} 2-\mathrm{T} 4 \mathrm{~b}$ & 51 & 5 & Japan & CR,5-y OS \\
\hline Fuwa [16] & 2008 & Retrospective study & Tongue cancer & $68[25-87]$ & 65 & $\mathrm{~T} 2-\mathrm{T} 4$ & 40 & 2.3 & Japan & CR,5-y OS \\
\hline Fuwa [23] & 2008 & Retrospective study & Tongue SCC & $63[25-87]$ & 71.6 & $\mathrm{~T} 2-\mathrm{T} 4 \mathrm{~b}$ & 88 & 4.4 & Japan & CR,3-y OS \\
\hline Fuwa [24] & 2008 & Retrospective study & OSCC & $67[25-89]$ & 66.4 & $\mathrm{~T} 2-\mathrm{T} 4 \mathrm{~b}$ & 134 & 3.8 & Japan & CR,3-y OS \\
\hline Hayashi [25] & 2017 & Retrospective study & OsCC & $82.5[80-88]$ & 38.7 & $\mathrm{~T} 2-\mathrm{T} 4 \mathrm{~b}$ & 31 & 3.1 & Japan & CR,3-y OS \\
\hline Homma [26] & 2016 & Retrospective study & Hypopharyngeal cancer & $60.6[45-75]$ & 96.7 & $\mathrm{~T} 1-\mathrm{T} 4 \mathrm{~b}$ & 92 & 5.2 & Japan & $5-y$ OS \\
\hline Kobayashi [27] & 2010 & Prospective study & OSCC & 61.7 & 63.6 & $\mathrm{~T} 2-\mathrm{T} 4$ & 22 & 1.5 & Japan & CR,5-y OS \\
\hline Kondo [28] & 2016 & Retrospective study & OSCC & $68[58-82]$ & 77.8 & $\mathrm{~T} 3, \mathrm{~T} 4 \mathrm{a}$ & 18 & 5 & Japan & CR,3-y OS \\
\hline Kovacs [15] & 2004 & Retrospective study & $\begin{array}{l}\text { Oral and oropharynx } \\
\text { cancer. }\end{array}$ & $66[38-89]$ & 53.8 & $\mathrm{~T} 1-\mathrm{T} 4$ & 52 & 5 & Germany & CR,3-y OS,5-y OS \\
\hline $\begin{array}{l}\text { Minamiyama } \\
{[29]}\end{array}$ & 2017 & Retrospective study & Tongue SCC & $63.5[34-87]$ & 69 & T2-T4a & 42 & 3.9 & Japan & CR,3-y OS,5-y OS \\
\hline Mitsudo [9] & 2014 & Retrospective study & OSCC & $59[28-87]$ & 69.6 & $\mathrm{~T} 2-\mathrm{T} 4 \mathrm{~b}$ & 112 & 3.9 & Japan & CR,3-y OS,5-y OS \\
\hline Mitsudo [14] & 2018 & Retrospective study & Tongue SCC. & $61[25-87]$ & 66.1 & $\mathrm{~T} 2-\mathrm{T} 4 \mathrm{~b}$ & 118 & 3.2 & Japan & CR,3-y OS,5-y OS \\
\hline Miyawaki [30] & 2012 & Retrospective study & OsCC & $69[39-84]$ & 57.5 & $\mathrm{~T} 1-\mathrm{T} 4$ & 40 & 6.8 & Japan & CR, 5-y OS \\
\hline Mukai [31] & 2014 & Retrospective study & Gingival carcinoma & $74[50-93]$ & 61.8 & $\mathrm{~T} 1-\mathrm{T} 4 \mathrm{~b}$ & 34 & 3 & Japan & CR,3-y OS,5-y OS \\
\hline Takayama [32] & 2016 & Retrospective study & Tongue SCC & $53[25-69]$ & 66.7 & $\mathrm{~T} 2-\mathrm{T} 4 \mathrm{a}$ & 33 & 3.6 & Japan & CR,3-y OS \\
\hline Tsukahara [33] & 2008 & Retrospective study & Oropharyngeal SCC & 63.1[44-85] & - & $\mathrm{T} 1-\mathrm{T} 4$ & 73 & 5 & Japan & $5-y$ OS \\
\hline Yoshizaki [34] & 2007 & Prospective study & HNSCC & $61.2 \pm 13.8$ & 91.8 & $\mathrm{~T} 2-\mathrm{T} 4$ & 49 & 2 & Japan & CR,3-y OS \\
\hline Yoshizaki [35] & 2009 & Retrospective study & Laryngeal Cancer & 63.9 & 92.7 & $\mathrm{~T} 2-\mathrm{T} 4$ & 41 & 3 & Japan & CR,3-y OS \\
\hline Bertino [36] & 2007 & Retrospective study & HNSCC & $39-75$ & 93.5 & $\mathrm{~T} 2-\mathrm{T} 4$ & 46 & 5 & Italy & CR, 5-y OS \\
\hline Bertino [37] & 2009 & Retrospective study & HNSCC & $38-74$ & 82.1 & $\mathrm{~T} 1-\mathrm{T} 4$ & 56 & 2 & Italy & CR \\
\hline Doi [38] & 2018 & Retrospective study & MSSCC & $63.5[31-82]$ & 16.7 & T3-T4b & 24 & 4.8 & Japan & CR,3-y OS \\
\hline Doweck [39] & 2008 & Retrospective study & OSCC & 58 & 81.9 & T3-T4 & 155 & - & USA & $5-y$ OS \\
\hline Hayashi [40] & 2019 & Retrospective study & Gingival SCC & - & 46.0 & $\mathrm{~T} 2-\mathrm{T} 4 \mathrm{~b}$ & 46 & 3.3 & Japan & CR,3-y OS \\
\hline Homma [41] & 2013 & Prospective study & MSSCC & $35-74$ & 79.6 & $\mathrm{~T} 2-\mathrm{T} 4 \mathrm{~b}$ & 54 & 6.4 & Japan & CR,5-y OS \\
\hline Kim [42] & 2013 & Retrospective study & Maxillary sinus carcinoma & $57[32-73]$ & 92.6 & T3-T4 & 27 & 6.4 & Korea & $5-y$ OS \\
\hline Krstevska [43] & 2012 & Retrospective study & Oropharyngeal SCC & & 90.8 & $\mathrm{~T} 2-\mathrm{T} 4$ & 65 & 1.2 & Macedonia & CR \\
\hline $\begin{array}{l}\text { Nakashimaa } \\
{[44]}\end{array}$ & 2011 & Retrospective study & Maxillary sinus carcinoma & $37-67$ & 60.0 & $\mathrm{~T} 4 \mathrm{a}-\mathrm{T} 4 \mathrm{~b}$ & 5 & 2 & Japan & CR \\
\hline Nozato [45] & 2019 & Retrospective study & OSCC & $55[35-81]$ & 61.5 & $\mathrm{~T} 2-\mathrm{T} 4 \mathrm{~b}$ & 26 & 5 & Japan & CR,5-y OS \\
\hline Takahara [46] & 2017 & Retrospective study & NNKTL & $53[21-70]$ & 83.3 & - & 12 & 6.8 & Japan & CR \\
\hline Yokoyama [47] & 2014 & Retrospective study & Paranasal sinus cancer & $66.5[45-84]$ & 76.1 & $\mathrm{~T} 3-\mathrm{T} 4 \mathrm{~b}$ & 46 & 3.1 & Japan & CR \\
\hline Total & $\begin{array}{l}34 \\
\text { studies }\end{array}$ & & & & & & 1890 & & & \\
\hline
\end{tabular}

RCT: randomized controlled trial; SCC: squamous cell carcinoma; OSCC: oral squamous cell carcinoma; HNSCC: head and neck squamous cell carcinoma; MSSCC: maxillary sinus squamous cell carcinoma; NNKTL: nasal natural killer/T-cell lymphoma; CR: complete response; 3-y OS: 3-year overall survival; 5-y OS: 5-year overall survival.

\section{Overall survival (OS)}

OS was defined as the time from the commencement of treatment until death or last follow-up time, which largely represents treatment efficacy. The 3-year OS rate was calculated from 15 studies including 836 subjects. As showed in Fig. 3A, the highest 3-year OS was 0.94 (95\% CI: 0.85-1.04), and the lowest one was 0.48 (95\% CI: 0.23-0.74). Despite high heterogeneity $\left(I^{2}=81.9 \%\right)$, the merged 3-year OS rate was still up to 0.75 (95\% CI: 0.68-0.82, $P<0.001$ ). Additionally, a random-effect model was employed (Fig. 3A). We further conducted subgroup analysis on the effect of IACRT on 3-year OS ratio of stage III and stage IV HNC. Data were extracted from 3 studies consisted of 140 patients in stage III and 177 patients in stage IV HNC, who underwent IACRT. The combined 3-year OS rate of stage III and stage IV were 0.75 (95\% CI: 0.53-0.97, $P<0.001)$ and 0.52 (95\% CI: $0.37-0.66, P=0.025)$, respectively. The heterogeneity of stage III and stage IV HNC were $91.6 \%$ and $73.0 \%$, respectively. Therefore, random-effect model was used (Figs. 3B and 3C).

Twenty studies with 1185 samples were included in the 5-year OS assessment, among them, 5 studies also provided 3-year OS rate. As showed in Fig. 4A, the 5-year OS rate was scattered among $0.37-0.90$, whose synthesis value was 0.68 (95\% CI: $0.61-0.75, P<0.001)$ just litter lower than that of 3-year OS, this indicated that there was no difference between 3-year OS and 5-year OS by using IACRT. In addition, we also analyzed the 5 -year OS in T3 and T4 subgroups. Three studies with 75 patients and 5 studies with 125 patients were included in T3 and T4 group, respectively. It should be noted that some studies classified T4 stage more detailed including $\mathrm{T} 4 \mathrm{a}$ and T4b. Therefore, we merged the OS ratio of $\mathrm{T} 4 \mathrm{a}$ and $\mathrm{T} 4 \mathrm{~b}$ of these studies in advance, and then used the combined OS value to merge with other studies. The combined 5-year OS rate of T3 was 0.87 (95\% CI: 0.73-1.01, $P=0.028$ ), however, the 5-year OS 


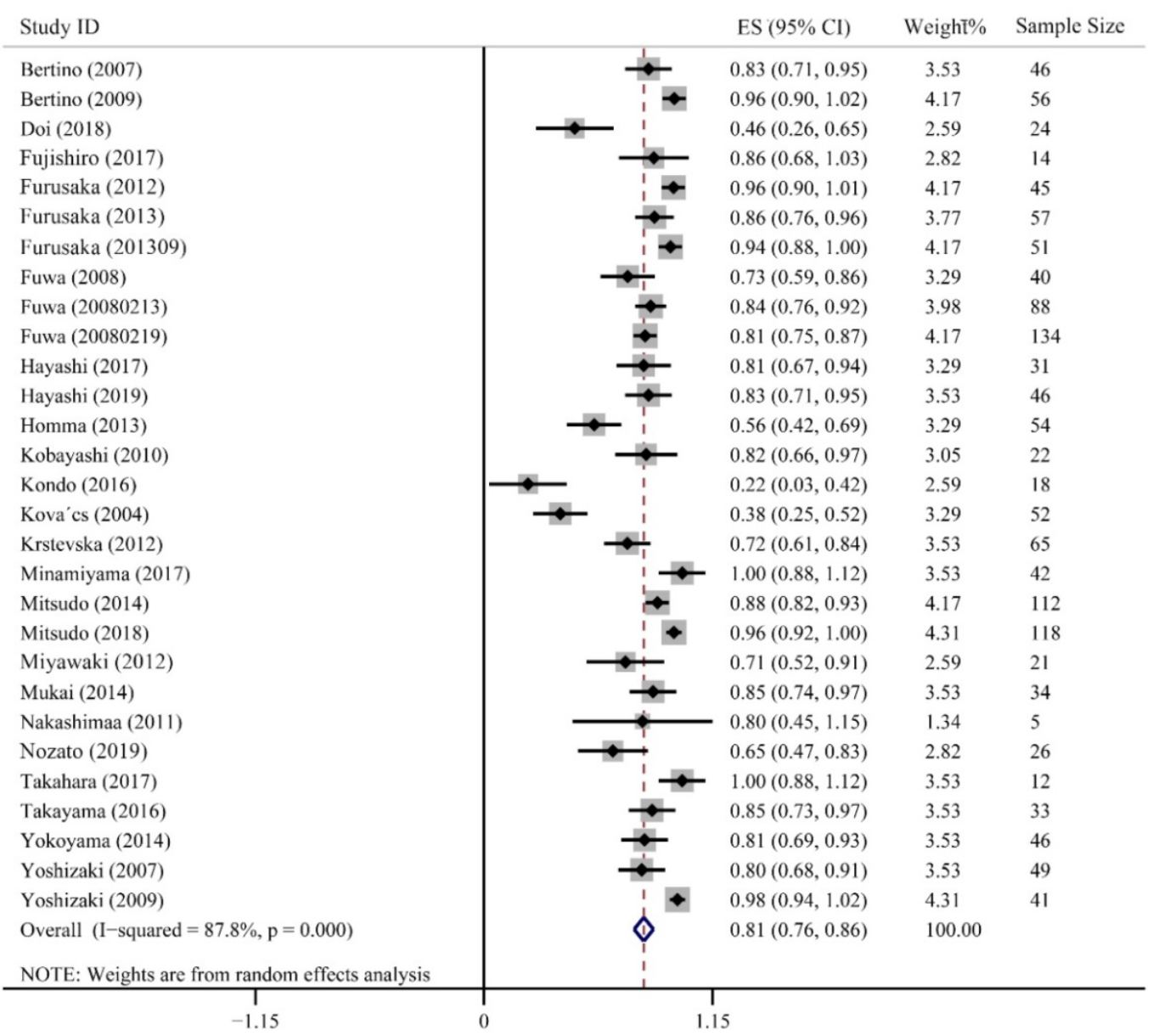

Figure 2. Forest plot of complete response.

rate was $0.53(95 \% \mathrm{CI}: 0.42-0.63, P=0.286)$ in $\mathrm{T} 4$ subgroup, which was much lower than T3 stage. A random-effect model was adopted in T3 subgroup as $I^{2}=72 \%$. However, a fixed-effect statistical model was used in T4 subgroup for low heterogeneity $\left(I^{2}=\right.$ $20.1 \%$ ) (Figs. 4B and 4C).

\section{Toxicity}

Toxicity can reflect the safety characteristic of treatment. It is regarded as an essential indicator of prognosis. Therefore, we extracted all side-effect data from 34 studies, which mentioned nearly 70 side-effect reactions. We reclassified and extracted 10 kinds of toxicities after excluding the side effects mentioned in less than three studies such as hyperuricemia, renal disorders, gastrointestinal diseases and osteoradionecrosis. Oral toxicities including oral diseases reported by 10 studies and mucositis reported by 21 studies were the major complications with the high incidence of 0.51 (95\% CI: $0.27-0.76$ ) and 0.59 (95\% CI: 0.42-0.76), respectively. The next two toxicities were dermatitis $(0.43,95 \% \mathrm{CI}$ :
0.23-0.63) and leukopenia (0.40, 95\% CI: 0.30-0.50), The incidence rates of general condition, anemia, nausea/vomiting and thrombocytopenia were lower than 0.35 . Fever and hepatic dysfunction were the last two toxicities with the lowest incidence rates of 0.12 (95\% CI: 0.06-0.18) and 0.06 (95\% CI: 0.02-0.11), respectively (Table 2). All these adverse effects were manageable and reversible. Moreover, we mapped the forest graph based on the incidence rates of these 10 toxicities (Fig. 5).

Table 2. Analytic results of toxicities.

\begin{tabular}{llll}
\hline Toxicity & Incidence & $95 \%$ CI & Number of studies Included \\
\hline Oral diseases & 0.515 & $0.266-0.765$ & 10 \\
Mucositis & 0.589 & $0.417-0.762$ & 21 \\
Leukopenia & 0.401 & $0.297-0.504$ & 22 \\
Dermatitis & 0.434 & $0.235-0.633$ & 14 \\
Anemia & 0.318 & $0.187-0.450$ & 20 \\
General condition & 0.339 & $0.202-0.475$ & 13 \\
Thrombocytopenia & 0.245 & $0.150-0.341$ & 17 \\
Nausea/vomiting & 0.263 & $0.152-0.374$ & 13 \\
Fever & 0.117 & $0.057-0.177$ & 8 \\
Hepatic dysfunction & 0.064 & $0.021-0.107$ & 7
\end{tabular}


A

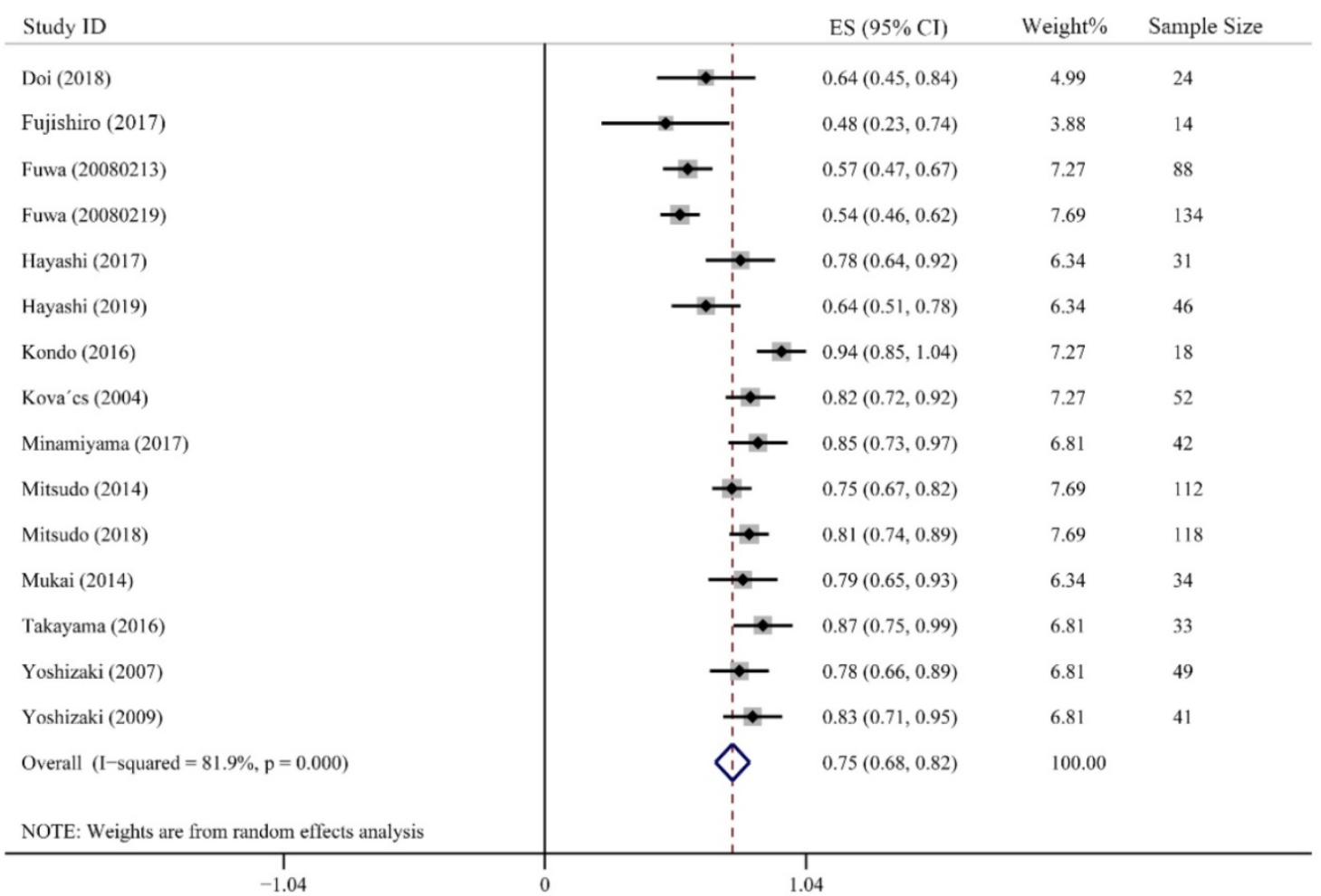

$\mathrm{B}$

\begin{tabular}{|c|c|c|c|}
\hline Study ID & ES $(95 \% \mathrm{Cl})$ & Weight $\%$ & Sample size \\
\hline Fuwa (20080213) & $0.67(0.54,0.80)$ & 32.22 & 48 \\
\hline Fuwa (20080219) & $0.63(0.51,0.75)$ & 32.99 & 63 \\
\hline Mitsudo (2018) & $0.95(0.87,1.03)$ & 34.79 & 29 \\
\hline Overall (I-squared $=91.6 \%, p=0.000)$ & $0.75(0.53,0.97)$ & 100.00 & \\
\hline NOTE: Weights are from random effects analysis & & & \\
\hline
\end{tabular}

$\mathrm{C}$

\begin{tabular}{|c|c|c|c|}
\hline Study ID & ES $(95 \% \mathrm{Cl})$ & Weight $\%$ & Sample size \\
\hline Fuwa (20080213) & $0.43(0.28,0.58)$ & 29.76 & 40 \\
\hline Fuwa (20080219) & $0.45(0.34,0.57)$ & 35.07 & 71 \\
\hline Mitsudo (2018) & $0.65(0.53,0.76)$ & 35.16 & 66 \\
\hline Overall (I-squared $=73.0 \%, \mathrm{p}=0.025)$ & $0.52(0.37,0.66)$ & 100.00 & \\
\hline NOTE: Weights are from random effects analysis & & & \\
\hline
\end{tabular}

Figure 3. Forest plots of 3-year overall survival (OS). (A) 3-year OS of all HNC. (B) 3-year OS of stage III HNC. (C) 3-year OS of stage VI HNC. 
A Study ID

Arcangeli (1983)

Bertino (2007)

Doweck (2008)

Furusaka (2012)

Furusaka (2013)

Furusaka (201309)

Fuwa (2008)

Homma (2013)

Homma (2016)

Kim (2013)

Kobayashi (2010)

Kova'cs (2004)

Minamiyama (2017)

Mitsudo (2014)

Mitsudo (2018)

Miyawaki (2012)

Mukai (2014)

Nozato (2019)

Tsukahara (2008)

Yokoyama (2014)

Overall $(\mathrm{I}-\mathrm{squared}=86.9 \%, \mathrm{p}=0.000)$

NOTE: Weights are from random effects analysis

\begin{tabular}{l|l|l}
1 & & \\
-1 & 0 & 1
\end{tabular}

B Study ID

ES $(95 \% \mathrm{CI})$

Weight $\%$ Sample Size

$\int_{-1}^{1} \quad 0_{1}$

\begin{tabular}{|c|c|c|c|}
\hline Study ID & $\mathrm{ES}(95 \% \mathrm{CI})$ & Weight $\%$ & Sample Size \\
\hline Furusaka (2013) & $0.96(0.89,1.03)$ & 42.70 & 31 \\
\hline Furusaka (201309) & $0.89(0.76,1.02)$ & 33.56 & 23 \\
\hline Tsukahara (2008) & $0.68(0.48,0.88)$ & 23.74 & 21 \\
\hline Overall $(\mathrm{I}-\mathrm{squared}=72.0 \%, \mathrm{p}=0.028)$ & $0.87(0.73,1.01)$ & 100.00 & \\
\hline NOTE: Weights are from random effects analysis & & & \\
\hline-1.03 & 03 & & \\
\hline
\end{tabular}

$\mathrm{C}$

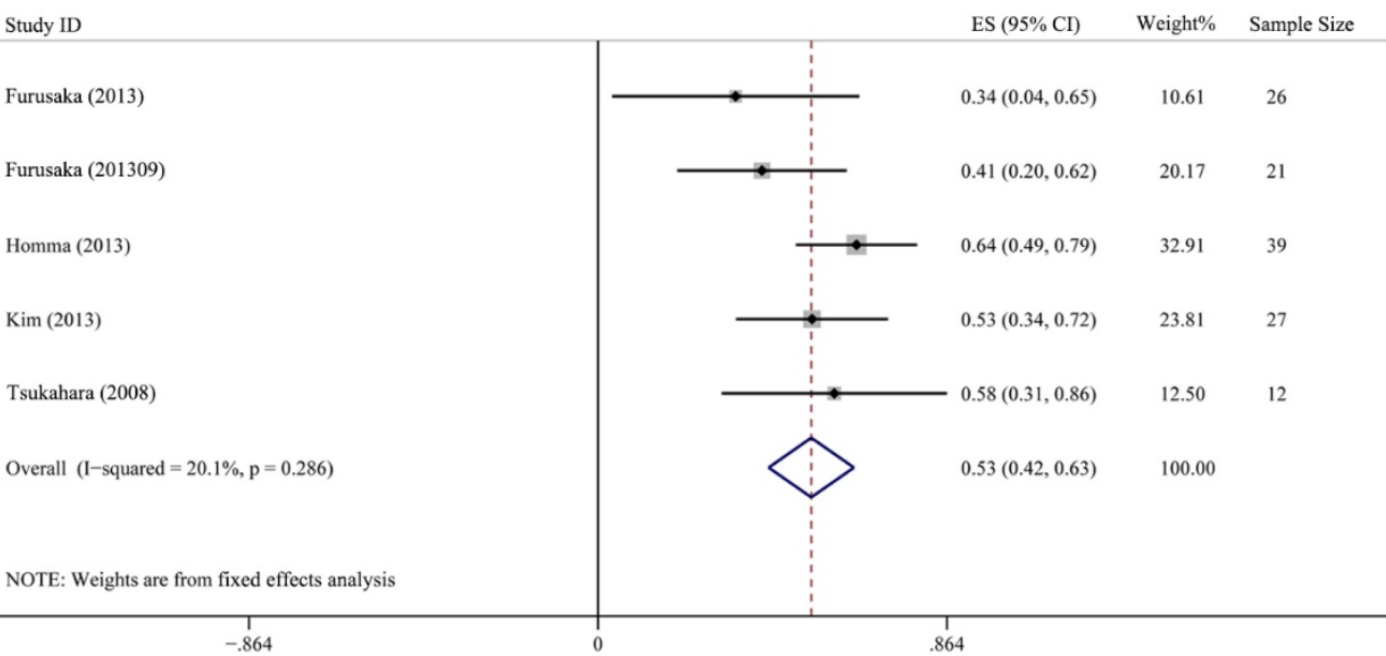

Figure 4. Forest plots of 5-year overall survival (OS). (A) 5-year OS of all HNC. (B) 5-year OS of T3 HNC. (C) 5-year OS of T4 HNC. 


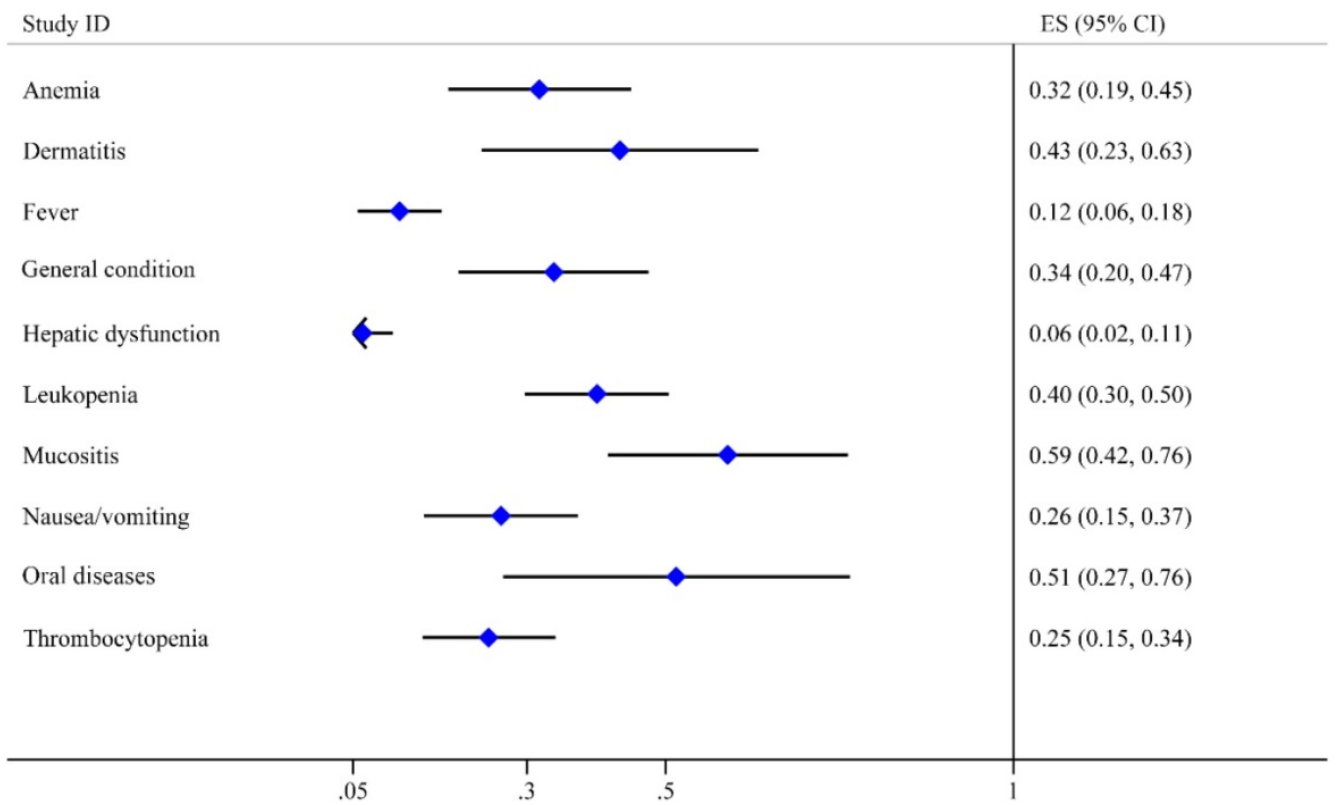

Figure 5. Forest plot of toxicities.

\section{Risk of bias across studies}

The $P$ value of Egger's test in CR combination was less than 0.001, indicating that significant publication bias exists. Therefore, we used trim-fill method and found that by filling 6 studies, the bias can be eliminated. The effect value of $\mathrm{CR}$ was 0.748 (95\% CI: 0.680 - 0.816) (Fig. 6A). However, we haven't found suitable study yet. The Egger's test of 3-year OS showed no significant publication bias for $P=0.969$, and the Begg's funnel plot was shown in Fig. 6B.

\section{Discussion}

In the current systematic review and meta-analysis, 34 clinical trials including 1890 subjects diagnosed as HNC were enrolled. We assessed the efficacy of IACRT by calculating CR and OS rates in HNC patients underwent IACRT. The combined CR, 3 -year OS and 5-year OS rates were all favorable. However, when assessing OS by classification of cancer into detail stages, the 3-year OS rate of stage III was higher than stage IV. Simultaneously, the 5-year OS rate of T3 patients was much higher than T4 patients. Additionally, oral diseases, mucositis, leukopenia and dermatitis were the common but reversible toxicities of IACRT. Therefore, we concluded that IACRT is efficacious for HNC which not only increases patient's survival rate, but also improves patient's quality of life.

In recent decades, IACRT was introduced to improve the outcome of patients with advanced HNC. Compared to conventional therapy, it is a friendly approach for preservation of organ and its function. Moreover, it can increase tumor responsiveness by increasing drug concentrations at the tumor site, meanwhile minimize the dose-limiting systemic side effects of drugs [48-50]. Concurrent combination of arterial infusion therapy with high dose of cisplatin and radiotherapy achieved $80 \%$ of $\mathrm{CR}$ in T3 and T4 HNC patients, which was only $61 \%$ in systemic chemotherapy combined with radiotherapy $[12,13]$. Another study analyzed the therapeutic results of retrograde superselective intra-arterial chemoradiotherapy in 118 patients with tongue cancer, and got a CR of 0.96 and a 3 -year OS of 0.82 , indicating that retrograde superselective IACRT for tongue cancer provided excellent overall survival and locoregional control [14]. Even though, poor tumor response and survival still exist in some studies. Kondo et al. achieved only 0.22 of CR rate in patients with $\mathrm{T} 3$ or $\mathrm{T} 4$ oral squamous cell carcinoma [28]. The 3-year OS reported by Fujishiro et al. was 0.48 in maxillary sinus carcinoma [19]. Therefore, whether IACRT has a better prognostic effect on HNC patients remains controversial. In the present study, we evaluated the efficacy of IACRT by assessing CR, 3 -years OS and 5-years OS in HNC patients. The combined CR ratio, 3-year OS and 5-year OS rates were $81 \%, 75 \%$ and $68 \%$, respectively, indicating that IACRT can get good control and provide high survival rates for HNC.

In clinical practice, cancers in different stages were treated by different therapies. For patients with early stage HNC, the treatment strategy is preferentially surgery. For the advanced HNC, a combined-modality treatment with surgery and radiotherapy or chemotherapy is clinically used. Therefore, we further analyzed 3-year OS rates in 


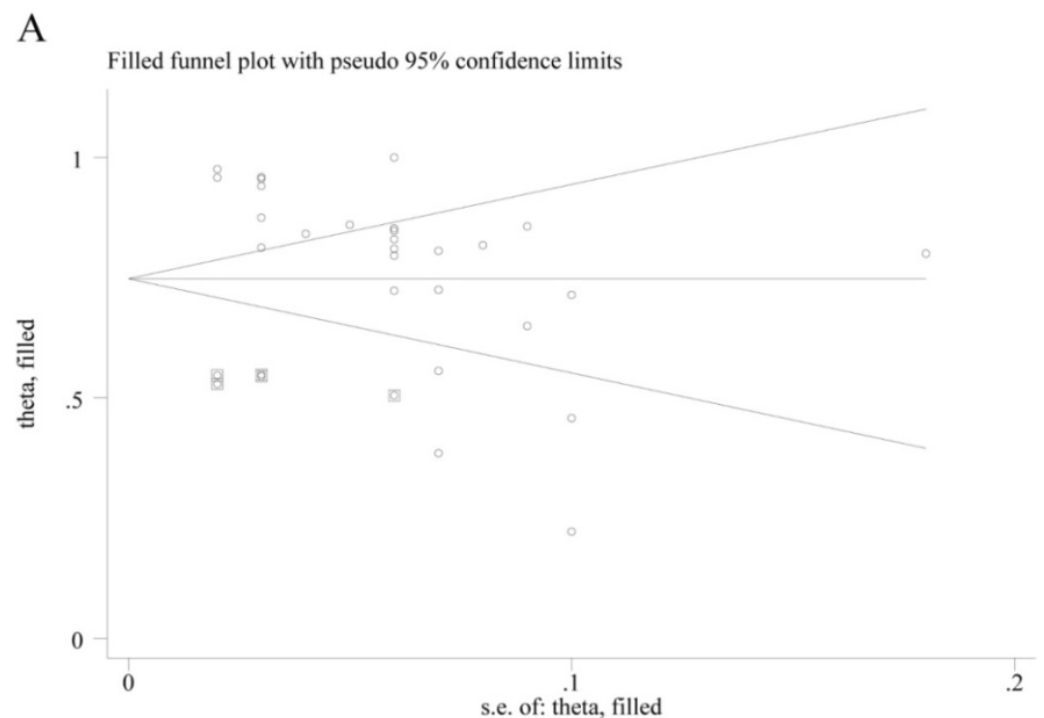

B

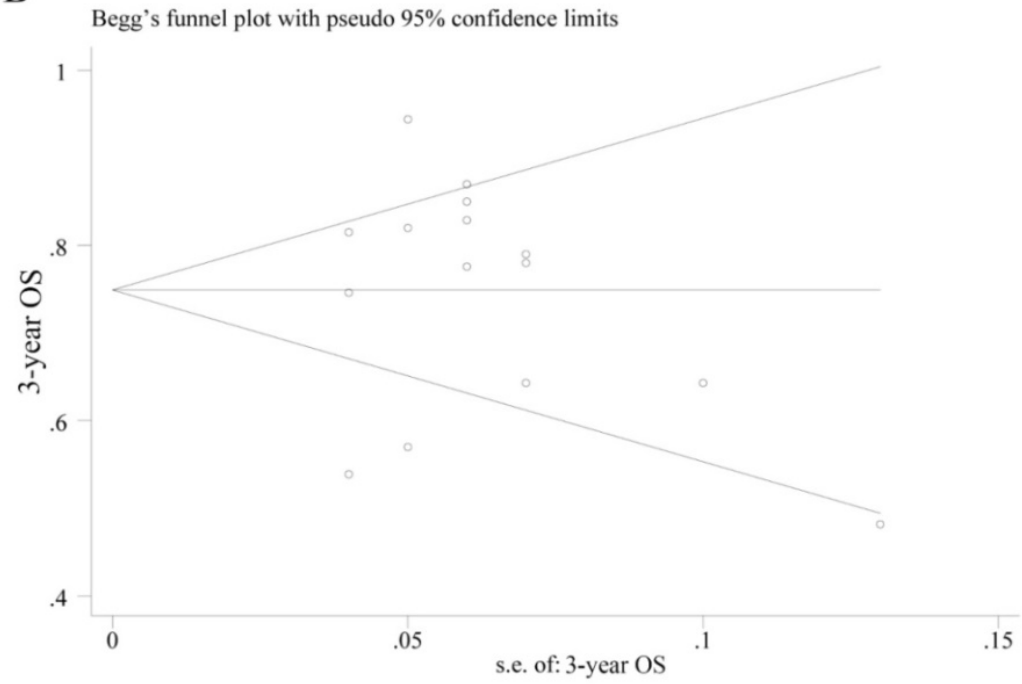

Figure 6. Publication bias on complete response (CR) and overall survival (OS). (A) Begg's funnel plot of the eligible studies involving CR combination; (B) Begg's funnel plot of the eligible studies involving 3-year OS.

stage III-IV HNC and 5-years OS rates in T3-4 HNC. The 3-year OS in stage III and stage IV cancer were $75 \%$ and $52 \%$ respectively. Identically, $87 \%$ and $53 \%$ of 5 -years OS were achieved in the patients with $\mathrm{T} 3$ and T4 HNC, respectively. A study on 201 patients with tongue SCC reported 64\% 3-year OS rates in stage III and $37 \%$ in stage IV cancer by systemic chemoradiotherapy [51]. Mroueh et al. compared 5 -year OS of operation therapy combined with radiotherapy (OT $+\mathrm{RT}$ ) and operation therapy combined with chemotherapy (OT + CT) among 360 patients with stage I-IV tongue cancers, and obtained a 5 -year OS rate of $61 \%$ in OT + RT group, and the $69 \%$ and $51 \%$ 5-year OS rates for patients with stage III and IV in OT + CT group [52]. Although these results were incomparable, the OS rate of the present study was better than radiotherapy or systemic chemotherapy. Moreover, a randomized trial on 140 HNC patients (oropharynx, maxillary antrum and intra-oral) compared the efficacy of IACRT and RT alone. The overall 5-year survival was $43 \%$ in the IACRT group and $25 \%$ in the group treated with radiation alone [53]. These findings indicated that IACRT was an efficient approach to improve outcomes of HNC patients, especially for the patients with stage III or T3 cancers.

Traditional systemic chemotherapy or intravenous chemotherapy increases the concentration of drugs in blood, causing myelosuppression, leukopenia, thrombocytopenia, nausea, vomiting and damage to multiple organs [54-56]. Some studies found no differences in locoregional control or overall survival between IACRT and IVCRT, but renal toxicity and late dysphagia were worse in IVCRT group comparing with IACRT [57]. Kobayashi et al. compared clinical outcomes and patient's quality of life between IACRT and surgery combined with radiotherapy in patients with tongue and mouth floor SCC, IACRT showed superior to surgery plus radiotherapy in terms of the survival rate and quality of life, indicating that IACRT should be preferred in managing advanced tongue and mouth floor SCC [58]. Even though, severe dermatitis and mucositis may occur within the radiation field during IACRT treatment, these toxicities were manageable and can be recovered by drug or professional oral management [59]. Other studies reported that mucositis and dysphagia were regarded to be inevitable but reversible [14, 32]. Additionally, systemic toxicities such as anemia, thrombocytopenia and leukopenia were also reported before [60-62]. Here, we summarized ten toxicities from the 34 studies, including oral diseases, mucositis, leukopenia, dermatitis, anemia, general condition, thrombocytopenia, nausea/vomiting, fever and hepatic dysfunction. All of them were manageable and reversible. Oral diseases, mucositis, dermatitis and leukopenia were the major toxicities with relatively high incidence. Therefore, more attention should be paid to prevent these toxicities for more favorable outcomes.

The limitations of our meta-analysis should be taken into account when interpreting the results. Firstly, among the included 34 studies, only one study 
is RCT, due to clinically inoperable, most studies did not have control group. Therefore, the results of these studies were incomparable. Secondly, most studies were conducted in Japan, only 7 studies were conducted in other countries, this may bring both regional and cultural bias. Thirdly, the investigation sample size of some studies was small, which would increase the heterogeneity of our study.

In conclusion, the results of this study suggested that IACRT is an efficient and safe therapy for HNC with manageable toxicities, especially for advanced HNC with stage III or T3. The toxicities such as oral diseases, mucositis, leukopenia, dermatitis, general condition and anemia should be concerned during treatment. However, due to the limitations of clinical studies and the differences in IACRT methods, more high-level and large-sample clinical trials are needed to further confirm the efficacy of ICART in the comprehensive treatment for HNC.

\section{Abbreviations}

HNC: head and neck cancer; IACRT: intro-arterial chemotherapy combined with radiotherapy; CR: complete response; OS: overall survival; CI: credible interval; IVCRT: intra-versus chemotherapy combined with radiotherapy; RCT: randomized controlled trial; SCC: squamous cell carcinoma; OSCC: oral squamous cell carcinoma; HNSCC: head and neck squamous cell carcinoma; MSSCC: maxillary sinus squamous cell carcinoma; NNKTL: nasal natural killer/T-cell lymphoma; OT: operation therapy; CT: chemotherapy; RT: radiotherapy.

\section{Acknowledgements}

This article was supported by the National Natural Science Foundation (Nos. 81570993 and 81671005).

\section{Author Contributions}

Y.H, RL.X: contributed to the study design, data search and extraction, statistical analyses and paper writing; LL.W, GY.Y: contributed to the interpretation of results and revise the manuscript. All authors read and approved the final manuscript.

\section{Competing Interests}

The authors have declared that no competing interest exists.

\section{References}

1. Fitzmaurice C, Allen C, Barber RM, Barregard L, Bhutta ZA, Brenner H, et al. Global, regional, and national cancer incidence, mortality, years of life lost, years lived with disability, and disability-adjusted life-years for 32 cancer groups, 1990 to 2015: a systematic analysis for the global burden of disease study. JAMA Oncol. 2017; 3: 524-48.
2. Siegel RL, Miller KD, Jemal A. Cancer Statistics, 2017. CA Cancer J Clin. 2017; 67: 7-30.

3. Torre LA, Bray F, Siegel RL, Ferlay J, Lortet-Tieulent J, Jemal A. Global cancer statistics, 2012. CA Cancer J Clin. 2015; 65: 87-108.

4. Yang B, Liu T, Qu Y, Liu H, Zheng SG, Cheng B, et al. Progresses and perspectives of anti-PD-1/PD-L1 antibody therapy in head and neck cancers. Front Oncol. 2018; 8: 563.

5. Cognetti DM, Weber RS, Lai SY. Head and neck cancer: an evolving treatment paradigm. Cancer. 2008; 113: 1911-32.

6. Baumann R, Depping R, Delaperriere M, Dunst J. Targeting hypoxia to overcome radiation resistance in head \& neck cancers: real challenge or clinical fairytale? Expert Rev Anticancer Ther. 2016; 16: 751-8.

7. Sroussi HY, Epstein JB, Bensadoun RJ, Saunders DP, Lalla RV, Migliorati CA, et al. Common oral complications of head and neck cancer radiation therapy: mucositis, infections, saliva change, fibrosis, sensory dysfunctions, dental caries, periodontal disease, and osteoradionecrosis. Cancer Med. 2017; 6: 2918-31.

8. Perri F, Ionna F, Muto P, Marzo MD, Caponigro F, Longo F, et al. Genetics and management of locally advanced carcinomas of the head and neck: role of altered fractionation radiotherapy. Future Sci OA. 2019; 5: Fso347.

9. Mitsudo $K$, Koizumi $T$, Iida $M$, Iwai $T$, Nakashima $H$, Oguri $S$, et al Retrograde superselective intra-arterial chemotherapy and daily concurrent radiotherapy for stage III and IV oral cancer: analysis of therapeutic results in 112 cases. Radiother Oncol. 2014; 111: 306-10.

10. Ii N, Fuwa N, Toyomasu Y, Takada A, Nomura M, Kawamura T, et al. A novel external carotid arterial sheath system for intra-arterial infusion chemotherapy of head and neck cancer. Cardiovasc Intervent Radiol. 2017; 40: 1099-104.

11. Gordon AC, Uddin OM, Riaz A, Salem R, Lewandowski RJ. Making the case: intra-arterial therapy for less common metastases. Semin Intervent Radiol. 2017; 34: 132-9.

12. Robbins KT, Kumar P, Wong FS, Hartsell WF, Flick P, Palmer R, et al. Targeted chemoradiation for advanced head and neck cancer: analysis of 213 patients. Head Neck. 2000; 22: 687-93.

13. Robbins KT, Storniolo AM, Kerber C, Vicario D, Seagren S, Shea M, et al. Phase I study of highly selective supradose cisplatin infusions for advanced head and neck cancer. J Clin Oncol. 1994; 12: 2113-20.

14. Mitsudo K, Hayashi Y, Minamiyama S, Ohashi N, Iida M, Iwai T, et al. Chemoradiotherapy using retrograde superselective intra-arterial infusion for tongue cancer: analysis of therapeutic results in 118 cases. Oral Oncol. 2018; 79: 71-7.

15. Kovács AF. Intra-arterial induction high-dose chemotherapy with cisplatin for oral and oropharyngeal cancer: long-term results. Br J Cancer. 2004; 90: 1323-8.

16. Fuwa N, Kodaira T, Furutani K, Tachibana H, Nakamura T. Treatment results of continuous intra-arterial CBDCA infusion chemotherapy in combination with radiation therapy for locally advanced tongue cancer. Oral Surg Oral Med Oral Pathol Oral Radiol Endod. 2008; 105: 714-9.

17. Moher D, Liberati A, Tetzlaff J, Altman DG. Preferred reporting items for systematic reviews and meta-analyses: the PRISMA statement. PLoS Med. 2009; 6: e1000097.

18. Arcangeli G, Nervi C, Righini R, Creton G, Mirri M, Guerra A. Combined radiation and drugs: the effect of intra-arterial chemotherapy followed by radiotherapy in head and neck cancer. Radiother Oncol. 1983; 1: 101-7.

19. Fujishiro Y, Nakao K, Watanabe K, Ebihara Y, Nakamura N, Mori H, et al. A new aspect of tri-modal therapy with superselective intra-arterial chemotherapy in maxillary sinus carcinoma. Acta Otolaryngol Suppl. 2007; 151-6.

20. Furusaka T, Asakawa T, Tanaka A, Matsuda H, Ikeda M. Efficacy of multidrug superselective intra-arterial chemotherapy (docetaxel, cisplatin, and 5-fluorouracil) using the Seldinger technique for tongue cancer. Acta Otolaryngol. 2012; 132: 1108-14.

21. Furusaka T, Matsuda A, Tanaka A, Matsuda H, Ikeda M. Laryngeal preservation in advanced piriform sinus squamous cell carcinomas using superselective intra-arterial chemoradiation therapy with three agents. Acta Otolaryngol. 2013; 133: 318-26.

22. Furusaka T, Matsuda A, Tanaka A, Matsuda H, Ikeda M. Superselective intra-arterial chemotherapy for laryngeal preservation in carcinoma of the anterior oropharyngeal wall. Acta Otolaryngol. 2013; 133: 194-202.

23. Fuwa N, Kodaira T, Furutani K, Tachibana H, Nakamura T, Nakahara R, et al. Arterial chemoradiotherapy for locally advanced tongue cancer: analysis of retrospective study of therapeutic results in 88 patients. Int J Radiat Oncol Biol Phys. 2008; 72: 1090-100.

24. Fuwa N, Kodaira T, Furutani K, Tachibana H, Nakamura T, Nakahara R, et al. Intra-arterial chemoradiotherapy for locally advanced oral cavity cancer: analysis of therapeutic results in 134 cases. Br J Cancer. 2008; 98: 1039-45.

25. Hayashi Y, Mitsudo K, Sakuma K, Iida M, Iwai T, Nakashima H, et al. Clinical outcomes of retrograde intra-arterial chemotherapy concurrent with radiotherapy for elderly oral squamous cell carcinoma patients aged over 80 years old. Radiat Oncol. 2017; 12: 112.

26. Homma A, Hatakeyama H, Mizumachi T, Kano S, Sakashita T, Kuramoto R, et al. A retrospective study of G-tube use in Japanese patients treated with concurrent chemoradiotherapy for hypopharyngeal cancer. PLoS ONE. 2016; 11: e0161734.

27. Kobayashi W, Teh BG, Sakaki H, Sato H, Kimura H, Kakehata S, et al. Superselective intra-arterial chemoradiotherapy with docetaxel-nedaplatin for advanced oral cancer. Oral Oncol. 2010; 46: 860-3. 
28. Kondo Y, Nagai K, Tamura T, Tagawa Y, Yamamoto K, Uemura Y, et al. Surgical resection or additional radiotherapy after superselective intra-arterial chemotherapy (docetaxel, cisplatin, and 5-fluorouracil) using the Seldinger technique and concurrent chemoradiotherapy for T3 or T4 oral squamous cell carcinoma. J Oral Maxillofac Surg Med Pathol. 2016; 28: 385-91.

29. Minamiyama S, Mitsudo K, Hayashi Y, Iida M, Iwai T, Nakashima H, et al. Retrograde superselective intra-arterial chemotherapy and daily concurrent radiotherapy for T2-4N0 tongue cancer: control of occult neck metastasis. Oral Surg Oral Med Oral Pathol Oral Radiol. 2017; 124: 16-23.

30. Miyawaki A, Hijioka H, Ikeda R, Ishida T, Nozoe E, Nakamura N. Analysis of the outcome of concurrent neoadjuvant chemoradiotherapy with S-1 compared to super-selective intra-arterial infusion for oral squamous cell carcinoma. Oncol Lett. 2012; 3: 995-1001.

31. Mukai Y, Hata M, Mitsudo K, Koike I, Koizumi T, Oguri S, et al. Radiation therapy with concurrent retrograde superselective intra-arterial chemotherapy for gingival carcinoma. Strahlenther Onkol. 2014; 190: 181-5

32. Takayama K, Nakamura T, Takada A, Makita C, Suzuki M, Azami Y, et al. Treatment results of alternating chemoradiotherapy followed by proton beam therapy boost combined with intra-arterial infusion chemotherapy for stage III-IVB tongue cancer. J Cancer Res Clin Oncol. 2016; 142: 659-67.

33. Tsukahara K, Yoshida T, Tokashiki R, Ito H, Hiramatsu H, Suzuki M. Useful combination of intra-arterial chemotherapy and radiation therapy for lateral oropharyngeal wall cancer. Acta Otolaryngol. 2008; 128: 578-82.

34. Yoshizaki T, Wakisaka N, Murono S, Kondo S, Shimizu Y, Takanaka T, et al. Intra-arterial chemotherapy less intensive than RADPLAT with concurrent radiotherapy for resectable advanced head and neck squamous cell carcinoma: a prospective study. Ann Otol Rhinol Laryngol. 2007; 116: 754-61.

35. Yoshizaki T, Kondo S, Wakisaka N, Murono S, Kitagawa N, Tsuji A, et al. Concurrent intra-arterial chemotherapy and radiotherapy for advanced laryngeal cancer. Ann Otol Rhinol Laryngol. 2009; 118: 172-8.

36. Bertino G, Benazzo M, Gatti P, Bernardo G, Corbella F, Tinelli C, et al Curative and organ-preserving treatment with intra-arterial carboplatin induction followed by surgery and/or radiotherapy for advanced head and neck cancer: single-center five-year results. BMC Cancer. 2007; 7: 62 .

37. Bertino G, Occhini A, Falco CE, Porta C, Corbella F, Colombo S, et al Concurrent intra-arterial carboplatin administration and radiation therapy for the treatment of advanced head and neck squamous cell carcinoma: short term results. BMC Cancer. 2009; 9: 313.

38. Doi H, Fujiwara M, Kitajima K, Tanooka M, Terada T, Noguchi K, et al. Clinical $\mathrm{T}$ staging is superior to fluorodeoxyglucose positron emission tomography for predicting local outcomes after intra-arterial infusion chemoradiotherapy for maxillary sinus squamous cell carcinoma. Nagoya J Med Sci. 2018; 80: 541-50

39. Doweck I, Robbins KT, Samant S, Vieira F. Intra-arterial chemoradiation for T3-4 oral cavity cancer: treatment outcomes in comparison to oropharyngeal and hypopharyngeal carcinoma. World J Surg Oncol. 2008; 6: 2.

40. Hayashi Y, Osawa K, Nakakaji R, Minamiyama S, Ohashi N, Ohya T, et al. Prognostic factors and treatment outcomes of advanced maxillary gingival squamous cell carcinoma treated by intra-arterial infusion chemotherapy concurrent with radiotherapy. Head Neck. 2019; 41: 1777-84

41. Homma A, Sakashita T, Yoshida D, Onimaru R, Tsuchiya K, Suzuki F, et al. Superselective intra-arterial cisplatin infusion and concomitant radiotherapy for maxillary sinus cancer. Br J Cancer. 2013; 109: 2980-6.

42. Kim WT, Nam J, Ki YK, Lee JH, Kim DH, Park D, et al. Neoadjuvant intra-arterial chemotherapy combined with radiotherapy and surgery in patients with advanced maxillary sinus cancer. Radiat Oncol J. 2013; 31: $118-24$

43. Krstevska V, Stojkovski I, Zafirova-Ivanovska B. Concurrent radiochemotherapy in locally-regionally advanced oropharyngeal squamous cell carcinoma: analysis of treatment results and prognostic factors. Radiat Oncol. 2012; 7: 78 .

44. Nakashima $\mathrm{T}$, Yasumatsu $\mathrm{R}$, Toh $\mathrm{S}$, Shiratsuchi $\mathrm{H}$, Kamitani $\mathrm{T}$, Shioyama $\mathrm{Y}$, et al. Advanced maxillary sinus cancer treated with concurrent chemoradiotherapy with intra-arterial cisplatin/docetaxel and oral s-1: own experience and literature review. Case Rep Oncol. 2011; 4: 492-8.

45. Nozato T, Koizumi T, Hayashi $\mathrm{Y}$, Iida M, Iwai $\mathrm{T}$, Oguri $\mathrm{S}$, et al. Thermochemoradiotherapy using superselective intra-arterial infusion for patients with oral cancer with cervical lymph node metastases. Anticancer Res. 2019; 39: 1365-73.

46. Takahara M, Nagato T, Kishibe K, Ueda S, Komabayashi Y, Yamashina M, et al. Novel treatment for early-stage nasal natural killer/T-cell lymphoma: intra-maxillary arterial infusion chemotherapy with concomitant radiotherapy. Hematol Oncol. 2017; 35: 158-62.

47. Yokoyama J, Ohba S, Fujimaki M, Anzai T, Kojima M, Ikeda K, et al. Impact of intra-arterial chemotherapy including internal carotid artery for advanced paranasal sinus cancers involving the skull base. Br J Cancer. 2014; 111: 2229-34.

48. Hiroaki N, Kenji M, Noriyuki Y, Iwai T. Thermochemoradiotherapy using superselective intra-arterial infusion for N3 cervical lymph node metastases of tongue cancer. J Cancer Res Ther. 2013; 9: 718-20.

49. Kobayashi W, Teh BG, Sakaki H, Sato H, Kimura H, Kakehata S, et al. Superselective intra-arterial chemoradiotherapy with docetaxel-nedaplatin for advanced oral cancer. Oral Oncol. 2010; 46: 860-3.

50. Sakuma K, Koizumi T, Mitsudo K, Ueda J, Hayashi Y, Iwai T, et al. Retrograde superselective intra-arterial chemoradiotherapy combined with hyperthermia and cetuximab for carcinoma of the buccal mucosa with N3 lymph node metastasis: a case report. Oral Radiol. 2019; 35: 77-83.

51. Fan KH, Lin CY, Kang CJ, Huang SF, Wang HM, Chen EY, et al. Combined-modality treatment for advanced oral tongue squamous cell carcinoma. Int J Radiat Oncol Biol Phys. 2007; 67: 453-61.

52. Mroueh R, Haapaniemi A, Grenman R, Laranne J, Pukkila M, Almangush A, et al. Improved outcomes with oral tongue squamous cell carcinoma in Finland. Head Neck. 2017; 39: 1306-12.

53. Arcangeli G, Nervi C, Righini R, Creton G, Mirri MA, Guerra A. Combined radiation and drugs: the effect of intra-arterial chemotherapy followed by radiotherapy in head and neck cancer. Radiother Oncol. 1983; 1: 101-7.

54. Sindhu SK, Bauman JE. Current concepts in chemotherapy for head and neck cancer. Oral Maxillofac Surg Clin North Am. 2019; 31: 145-54.

55. Busch CJ, Tribius S, Schafhausen P, Knecht R. The current role of systemic chemotherapy in the primary treatment of head and neck cancer. Cancer Treat Rev. 2015; 41: 217-21.

56. Adelstein DJ. Systemic chemotherapy for squamous cell head and neck cancer. Expert Opin Pharmacother. 2003; 4: 2151-63

57. Rasch CR, Hauptmann M, Schornagel J, Wijers O, Buter J, Gregor T, et al. Intra-arterial versus intravenous chemoradiation for advanced head and neck cancer: results of a randomized phase 3 trial. Cancer. 2010; 116: 2159-65.

58. Kobayashi W, Kukobota K, Ito R, Sakaki H, Nakagawa H, Teh BG. Can superselective intra-arterial chemoradiotherapy replace surgery followed by radiation for advanced cancer of the tongue and floor of the mouth? J Oral Maxillofac Surg. 2016; 74: 1248-54.

59. Hayashi Y, Nakamura T, Mitsudo K, Yamaguchi H, Ono T, Azami Y, et al. Retrograde intra-arterial chemotherapy and daily concurrent proton beam therapy for recurrent oral cavity squamous cell carcinoma: analysis of therapeutic results in 46 cases. Head Neck. 2016; 38: 1145-51.

60. Li Y, Zhang J. Expression of mutant p53 in oral squamous cell carcinoma is correlated with the effectiveness of intra-arterial chemotherapy. Oncol Lett. 2015; 10: 2883-7.

61. Sugimoto H, Hatano M, Yoshida S, Sakumoto M, Kato H, Ito M, et al. Efficacy of concurrent superselective intra-arterial chemotherapy and radiotherapy for late-stage squamous cell carcinoma of the temporal bone. Clin Otolaryngol. 2015; 40: 500-4.

62. Kitajima H, Oshima M, Iwai T, Ohhara Y, Yajima Y, Mitsudo K, et al. Computational fluid dynamics study of intra-arterial chemotherapy for oral cancer. Biomed Eng Online. 2017; 16: 57. 